\title{
DISCUSSION
}

\section{Development and applications of a synthetic material to simulate soft sedimentary rocks}

\author{
B. INDRARATNA (1990). Géotechnique 40, No. 2, 189-200
}

I. W. Johnston, Department of Civil Engineering, Monash University, Melbourne

In this Paper, Dr Indraratna argues that simulated rock expands the scope of geotechnical research, but in order to obtain meaningful representative behaviour certain similitude requirements must be met. The Author goes on to describe the development and applications of an artificial soft rock considered to be appropriate for sedimentary rocks such as limestones, sandstones and shales. Mention is made of various modelling materials that have been used in the past, including a brief mention of the work of Johnston \& Choi (1986). The Author noted that these investigators developed a model material that could simulate the consolidation behaviour of a real mudstone but did not mention that this same material could model much more than this one aspect of performance. What the Author failed to appreciate was that the consolidation process, or stress history, is a vital part of the similitude requirements for a model material for a rock, especially for a soft rock.

The behaviour and properties of geotechnical materials are highly dependent on stress history. In soil mechanics terms, the differences between normally consolidated and overconsolidated behaviour are well known with the normally consolidated state generally displaying ductile and contractant characteristics and the overconsolidated state tending to be much more brittle and dilatant. The two types of behaviour are generally observed at confining pressures which are separated by the maximum past overburden pressure. In the case of both soft and hard rocks, a very similar dependence on confining pressure can be observed with low confining pressures producing brittle, dilatant behaviour comparablc to overconsolidated soils and high confining pressures producing ductile, contractant behaviour comparable to normally consolidated soils. This can be observed in the classic results of von Karman (1911) as presented by Jaeger \& Cook (1976), along with the results presented by many others. These two types of behaviour are usually observed at confining pressures which, in rock mechanics terms, are either side of the brittle-ductile transition pressure.

For rocks, the confining pressures usually required to reach the brittle-ductile transition for the development of normally consolidated behaviour are much greater than are required for soils. For soft rocks these pressures may be commonly obtained in practice, whereas for hard rocks such pressures are much rarer. It follows that while soft rocks may show both brittlc and ductilc behaviour, the behaviour of hard rocks is more likely to be governed by the brittle, dilatant characteristics more typical of the overconsolidated state.

On the basis of this argument, it would seem important that any model material for a rock must display at least the brittle and dilatant characteristics expected for investigations carried out at low confining pressures. Furthermore, because of the stress concentrations that can occur, certain regions of a physical model may become ductile and contractant to produce a quite different response. This is particularly important with the softer rocks as may be observed in the model pile test results of Johnston \& Choi (1985) in which the soft rock responded with both types of behaviour to influence greatly the mechanisms of failure.

It follows that in addition to the various similitude parameters considered by Dr Indraratna, it is believed that it is important to obtain some form of similitude with regard to stress history and the effect this has on ductility and volume response. Although not applicable to the current discussion, this requirement must be considered even more critical when dealing with a wet, if not saturated model rock. Depending on the rate at which load is applied, the tendency to contract or dilate could have a dramatic influence on generated pore water pressures. As these pore water pressures may be of the same order as the strength of a soft rock, they could significantly affect performance as was demonstrated by Chiu et al. (1983).

While the Author has shown a range of results which show favourable comparisons between 
gypstone and various other natural rock materials, these comparisons may be obtained with a wide range of synthetic materials. However, it is Fig. 5 which causes the most concern. This figure shows that gypstone displays triaxial compression data which appears very similar to normally consolidated soils. Even for relatively low confining pressures (e.g. $\sigma_{3}=$ $0.8 \mathrm{MPa}$ ) a ductile response is shown. There are insufficient results presented to permit an assessment of volume change response, but it is suspected that because of the method of manufacture this may be contractant also. It would normally be expected that even a soft rock, tested at such a low confining pressure would produce a brittle, dilatant response.

The Author then considers the application of gypstone as a model material in an investigation into the performance of fully grouted passive bolts under a range of conditions. It is clear that these bolts have a large influence on the strength of the gypstone under uniaxial compression. However, as the tests were conducted at zero confining pressure, would it not be more appropriate to use a model rock which had brittle, dilatant characteristics? A model material which has ductile, and possibly contractant characteristics is likely to produce mechanisms and therefore results significantly different from a real rock.

It may be worth noting that in the development of their synthetic soft rock, Johnston \& Choi considered many other constituent materials including numerous forms of plasters and cements. Various preparation procedures were also considered, including the use of vibrations and suction to remove entrapped air. However, while some of these trials produced an apparent rock-like material, they all failed to reproduce the overconsolidated/normally consolidated (or brittle and dilatant/ductile and contractant) behaviour which was considered essential for such a model. This stress history, replicating the geological process of consolidation, could only be obtained by applying high calibrated compression stresses to the model constituents during manufacture and before curing.

\section{Author's reply}

Dr Johnston discusses the brittle-ductile phenomenon as influenced by the confining pressure or stress history. As mentioned in the conclusion, the model material discussed in the Paper simulates weak sedimentary rock masses, more correctly those which demonstrate elasto-plastic yield behaviour rather than an elastic, brittle post-peak response. It is true that the majority of rock samples tested in the laboratory would indicate a brittle nature, for instance, as presented by Jaeger \& Cook (1979) for a relatively strong (stiff) intact marble. However, small laboratory specimens are certainly not representative of the actual field behaviour, which is influenced by a much larger scale effect. Hoek \& Brown (1980) not only explained the transition from an intact rock to a heavily jointed rock mass with increasing scale, but did mention that ductility can be pronounced in weathered rocks, heavily jointed rock masses and some weak rocks, including evaporites, under normal engineering conditions. Obviously, full scale tests on weak rock masses are difficult to perform due to the scale of operation, hence test data on large-scale rock mass behaviour are extremely limited, in comparison with the abundant data available for laboratory tested small scale samples. Therefore, use of model material certainly expands the scope of geotechnical research in representing the behaviour of nonintact weak rock masses in the field.

As pointed out by Dr Johnston, laboratory samples of most intact rocks generally indicate an initially elastic, post-peak brittle behaviour. However, with the enhanced degree of jointing and/or folding (over-stressing) associated in the field for a truly representative larger scale sample, greater ductility and elasto-plastic yielding are expected. One typical example is the weathered and fractured rock mass encountered during the construction of the Enasan Tunnel (Ito, 1983). Another instance is the fissured mudstone with mica partings described by Houghton (1976) as a very low rock quality designation material, encountered in the Kielder experimental tunnel.

Considering these field aspects, weak soft rock masses should be modelled by a synthetic material, which docs not show pronounced brittle behaviour. In such cases, Plaster of Paris or gypsum cement and sand mixtures (e.g. Heuer \& Hendron, 1969, 1971; Rosenblad, 1968; Stimpson, 1970) and occasionally coal (e.g. Maloney, 1984; Kaiser et al., 1985) may be utilized for appropriate modelling, particularly to investigate the failure mechanisms near tunnel openings. One objective of making gypstone considerably weaker than the prototype rocks was to induce yielding at reduced stress levels than those encountered in the field, in order to simulate in the laboratory, for instance, the behaviour of weak rock masses over-stressed at considerable depths (i.e. extensive plastic zones). The effectiveness of this synthetic material in simulating tunnelling difficulties associated with poor ground conditions (yielding soft rock) has been discussed in more detail by Indraratna \& Kaiser (1990).

Figure 5 illustrates the stress-strain behaviour of gypstone in triaxial compression. It is true that the stress-strain curves indicate a ductile response at confining pressures $\geqslant 0.8 \mathrm{MPa}$, but with some post-peak strength loss. However, Fig. 4 clearly 
indicates that gypstone is truly brittle at zero confining stress. I regret that the stress-strain curves of gypstone for $\sigma_{3}<0.8 \mathrm{MPa}$ are not presented in Fig. 5. Nevertheless, the brittle-ductile transition for gypstone does occur at a confining stress level slightly less than 0.6 MPa. Dr Johnston has mentioned that $0.8 \mathrm{MPa}$ is a relatively low confining stress, and that in order to model a typical rock, a brittle-dilatant response must be shown by the model material at such confining stress levels. In my opinion, this argument is not always justified. The magnitude of the applied confining stresses can be considered in contrast to the unconfined compressive strength of the material being tested. Even in the case of laboratory triaxial tests (small scale) conducted on intact Carrara Marble (results of von Karman, 1911, presented by Jaeger \& Cook, 1979), ductile behaviour is exhibited at a confining stress of about $7 \mathrm{kp}$.s.i. (48 $\mathrm{MPa}$ ), which is approximately $35 \%$ of its uniaxial strength of $20 \mathrm{kp}$.s.i. (138 MPa). Clearly, for relatively weak soft rock masses in the field this percentage can become considerably less. Therefore, in relation to the small uniaxial compressive strength of artificial gypstone ( $3.4 \mathrm{MPa}$ ), a confining stress of $0.8 \mathrm{MPa}$ $(24 \%)$ cannot simply be regarded as too low. Considering the similitude aspects of strength, the corresponding confining stress applicable to a prototype rock mass in the field can be several factors greater than $0.8 \mathrm{MPa}$, depending on the compressive strength ratio between the prototype and gypstone. Although the results of volume change are not discussed in the Paper, gypstone reveals dilation during shearing, with an estimated variable dilatant coefficient of $1.5-2.0$ (Indraratna \& Kaiser, 1988). A dilatant coefficient of 1.0 typically represents the condition of zero volumetric change.

In the absence of a confining stress, brittle mode of failure can be expected for even the weakest soft rocks. As mentioned earlier, gypstone indicates a definite brittle behaviour in uniaxial compression (Fig. 4), and for confining stresses less than 0.6 $\mathrm{MPa}$. In reality, the absence of a confining stress is representative of the rock material in close proximity to a tunnel wall (zero or nominal radial stress). Under passive bolting (no initial pre-stressing), stabilized rock subjected to little or no confining stress may also behave in a brittle manner at failure. As shown in Fig. 12, the reinforced gypstone blocks do indicate brittle failure in uniaxial compression. Considering these observations, gypstone model material can be used effectively to predict the behaviour of a reinforced opening excavated in a weak or fractured rock mass (Indraratna \& Kaiser, 1990), including the failure modes near the tunnel wall (Indraratna, 1990).

\section{REFERENCES}

Chiu, H. K., Johnston, I. W., \& Donald, I. B. (1983). Appropriate techniques for triaxial testing of saturated soft rock. Int. J. Rock Mech. Min. Sci. \& Geomech. Abstr. 20, 107-120.

Heuer, R. E. \& Hendron, A. J. (1969). Geomechanical model study of the behaviour of underground openings in rock subjected to static loads. US Corps of Engineers, Report N-69-1, No. 1, Contract DACA39-67C-0009.

Heuer, R. E. \& Hendron, A. J. (1971). Geomechanical model study of the behaviour of underground openings in rock subjected to static loads. US Corps of Engineers, Report N-69-1, No. 2, Contract DACA39-67C-0009.

Hoek, E. \& Brown, E. T. (1980). Underground excavations in rock. London: Institute of Mineralogy and Metallurgy.

Houghton, D. A. (1976). The role of rock quality indices in the assessment of rock masses. Proc. Symp. Exploration for Rock Engineering, Johannesburgh, pp. $129-135$.

Indraratna, B. (1990). Stability assessment of reinforced tunnel opening using laboratory models. Proc. 10th Southeast Asian Geotech. Conf., 1, Taipei, pp. 527532.

Indraratna, B. \& Kaiser, P. K. (1988). Stabilization of underground openings in jointed rock by fully grouted bolts. 15th Can. Symp. on Rock Mech., Toronto, pp. 195-206.

Indraratna, B. \& Kaiser, P. K. (1990). Design for grouted rock bolts based on the convergence control method. Int. J. Rock Mech. Min. Sci. \& Geomech. Abstr. 27, No. 4, pp. 269-281.

Ito, Y. (1983). Design and construction by NTAM through Chogiezawa Fault Zone for Ensan Tunnel on the Central Motorway (in Japanese). Tunnels and $U$ ituerground 14, 7-14.

Jaeger, J. C. \& Cook, N. G. W. (1976). Fundamentals of rock mechanics (2nd Edn). New York: Wiley.

Jaeger, J. C. \& Cook, N. G. W. (1979). Fundamentals of rock mechanics (3rd Edn). London: Chapman and Hall.

Johnston, I. W. \& Choi, S. K. (1985). Failure mechanisms of foundations in soft rock. Proc. 11th Int. Conf. Soil Mech. \& Fndn Engng, San Francisco, 3, 1397-1400, Rotterdam: Balkema.

Johnston, I. W. \& Choi, S. K. (1986). A synthetic soft rock for laboratory model studies Géotechnique 36, 251-263.

Kaiser, P. K., Guenot, A., \& Morgenstern, N. R. (1985). Deformation of small tunnels-IV, behaviour during failure. Int. J. Rock Mech. Min. Sci. \& Geomech. Abstr. 22, 141-152.

Von Karman, T. (1911). Festigkeitsversuche unter allseitigem Druck. Z. Ver. dt Ing. 55, 1749-1757.

Maloney, S. M. (1984). An assessment of deformation monitoring practice in underground excavations in weak rock by model tests. MSc thesis, University of Alberta.

Rosenblad, J. L. (1968). Development of rocklike model material. Proc. 10th US Symp. on Rock Mechanics, Austin, Texas, pp. 331-361.

Stimpson, B. (1970). Modelling materials for engineering rock mechanics. Int. J. Rock Mech. \& Min. Sci. 7, $71-121$ 